https://helda.helsinki.fi

\title{
Metal Detecting in Focus Again - A Response to Immonen and \\ Kinnunen, Winkley, Hardy, and Rogerson
}

\section{Thomas, Suzie}

2016

Thomas, S 2016 , ' Metal Detecting in Focus Again - A Response to Immonen and

Kinnunen, Winkley, Hardy, and Rogerson ', Public Archaeology, vol. 15 , no. 4 , pp.

245-248 . https://doi.org/10.1080/14655187.2016.1429786

http://hdl.handle.net/10138/305546

https://doi.org/10.1080/14655187.2016.1429786

acceptedVersion

Downloaded from Helda, University of Helsinki institutional repository.

This is an electronic reprint of the original article.

This reprint may differ from the original in pagination and typographic detail.

Please cite the original version. 
Metal detecting in focus again: A response to Immonen and Kinnunen, Winkley, Hardy and Rogerson

Suzie Thomas

Department of Cultures, University of Helsinki, Helsinki, Finland

PL 59, Helsingin yliopisto, FI-00014, Finland.

suzie.e.thomas@helsinki.fi

$+358504487450$

Suzie Thomas is Professor of Cultural Heritage Studies at the University of Helsinki, Finland. She is Principal Investigator of SuALT - The Finnish Archaeological Finds Recording Linked Open Database (Fi: Suomen arkeologisten löytöjen linkitetty tietokanta), http://blogs.helsinki.fi/sualt-project/, which is funded by the Academy of Finland, decision numbers 310854, 310859, and 310860. She has studied metal detecting and archaeology since doing her doctoral research on the topic at Newcastle University, UK (completed 2009). 


\section{Metal detecting in focus again: A response to Immonen and Kinnunen, Winkley, Hardy, and Rogerson}

The current collection in Public Archaeology is by no means the first time a journal or other academic publication has chosen to focus on the issue of metal detecting and its impact on archaeology (consider for example Thomas \& Stone, 2009; Campbell \& Thomas, 2013, or Pitblado \& Shott, 2015 for a wider overview of non-professional engagements with material culture, not only metal detecting). However, the revisiting, or indeed broadening of the range of debate is welcome. In this collection of papers, we see not only an assortment of (European and Eurasian) geographic locations presented - each with their relative and different challenges, but we also see a diverse range of research methods and approaches discussed and tested. Hence in this collection we learn of the results from questionnaire surveys of different interest groups, the 'go along' ethnographic method applied to metal detectorists, analysis of online open data, and a historical study utilizing the literature and archival sources.

Visa Immonen and Joonas Kinnunen contribute by shedding further light on the situation in Finland. The research they carried out, in 2014, was significant for being the first such survey carried out in the country. They suggest that their research, although primarily collecting data through questionnaire survey - which they acknowledge did not allow for accessing 'such complex phenomena as emotions' - has nonetheless built upon previous ethnographically framed research (my own doctoral research included). Their study of metal detectorists has indeed provided new dimensions to our understanding of the hobbyists themselves. It also brings this and similar research previously published in Finnish (Immonen \& Kinnunen, 2014; Siltainsuu \& Wessman, 2014) to a more international readership, and helps to share more widely the Finnish experience.

The issue of how to expand our ethnographic understandings of metal detectorist communities is taken even further and tackled head-on by Felicity Winkley, inspired by her recent doctoral research in England. The 'go-along' method is a fruitful approach gaining popularity 
among ethnologists and others in a range of settings (e.g. Suopajärvi, 2014), and it is extremely encouraging to see this method applied to metal detectorists. As Winkley explains, this enabled her to explore perceptions of landscape and sense of place that would likely not have been possible otherwise through more static methods such as surveys or interviews carried out off location. This approach is being applied now in other countries too, for example by Anna Wessman in her study of metal detectorists in the Häme region of Finland (Wessman, forthcoming). It will be interesting to see the application of this approach further develop over the next years, and to see what light it sheds on the understanding of metal detectorist perspectives.

In the third paper of this collection, Sam Hardy deploys an approach he previously attempted on a truly global scale (Hardy, 2017) as a means of making sense of the state of metal detecting in Belarus, Poland, Russia and Ukraine. It is good to see that Hardy acknowledges the potential limitations of this approach. Even with the reasoning of comparing figures from other countries, for example, for the percentages of discussion forum and social media participants likely to be regularly active hobbyists, I am still inclined to urge caution when interpreting these figures. This is not least due to the fact that there is only internet access in ' 76.4 per cent of Russia, 73.3 per cent of Poland, 71.1 per cent of Belarus and 52.5 per cent of Ukraine'. More informative in my view are the attitudes presented in online discussion towards the hobby in many of the forums that Hardy has analysed, including how some people find ways of getting around preventative laws. Hardy's suggestion of 'legal nihilism' - a negative attitude towards the law which incorporates a severe doubt that the law benefits society - is also intriguing, and illustrates the importance of understanding both legal hobbyist activities and illegal looting practices within the social and cultural contexts of their respective societies.

Finally, Andrew Rogerson provides a brief but insightful account of the development of archaeologist/detectorist cooperation in Norfolk, England. Many of us interested in this field readily acknowledge the tremendous contribution of the late Tony Gregory and his colleagues to the very 
concept of recording metal-detected finds (e.g. Bland, 2005: Thomas, 2013). The article is tantalizing in its promise that more information about this formative period will be available soon (e.g. Wade-Martins, forthcoming), and demonstrates that this tradition of active engagement with metal detectorists and the archaeological information they generate, is something of a continued tradition in East Anglia. Rogerson's conclusion reminds us that not only does personal initiative allow collaborative initiatives like that witnessed for decades in Norfolk to flourish, but also working environments which encourage such out-of-the-box thinking.

It is certainly true that the metal detecting 'scene' (or really 'scenes'), and what we as researchers know about it, is developing rapidly. Hardy and others (e.g. Fernández Cacho \& García Sanjuán, 2000, on Spain) shed light on the darker side of metal detecting - the looting, illicit trade and severe loss of archaeological knowledge as a result of it. Hardy suggests ways to harness already-accessible data to pinpoint robust evidence for this, and it is clearly an approach that is still subject to fine-tuning and a great degree of estimation and approximation in its current form.

The threat of violence towards archaeologists that Hardy notes is deplorable, and surely points to greater societal problems in the countries that he studies in his article. At the same time, many other metal detectorists, in different countries and jurisdictions than these, seem much more interested in contributing (legally) to archaeological knowledge - as Winkley noted. In this light, another open data approach that can involve metal detecting is the utilization of data generated by metal detectorists and other non-professionals discovering material of archaeological interest. The best known, referenced by Rogerson, Winkley and even Immonen and Kinnunen, is the Portable Antiquities Scheme in England and Wales. In very recent years comparable databases are emerging in countries where the legislation allows for such 'citizen science' engagement, such as Flanders (Deckers, et al., 2016) and Denmark (Dobat \& Jensen, 2016). From September 2017 I have been Principal Investigator in a new open source data project in Finland, which aims to support the current efforts of the country's National Board of Antiquities with a new research infrastructure 
which allows individuals to register their finds, while also facilitating research and connecting to data in other parts of Europe. Hence on a national level, the work of Immonen and Kinnunen and others has been invaluable in augmenting our knowledge about Finnish metal detectorists, to which we hope our own project will add even more knowledge. As with all finds recording schemes, and this includes transnational angles in the operational infrastructure level to make sure different datasets are comparable for research.

I suspect there is also a transnational angle in the nature of the metal detecting hobby itself with such as 'detecting tourists' active as well as trade of objects - both legally and, regrettably, illegally - across national borders. As we have seen in these papers, we have many research methods available to us, and as a result more and more data available. My final point of consideration is to remember that, even as we increasingly take metal detectorists as a 'subject' or 'object' of study, we remember that they are also people with views, sensibilities and sensitivities. As K. Anne Pyburn noted of archaeology: 'When archaeology is constructed in opposition to collecting, religion, entertainment, or descendent communities, we lose sight of how our practice not only affects, but even creates impermeable boundaries around potentially antagonistic groups' (Pyburn, 2011: 35). As with all communities that come into contact with archaeological work, we must be careful not to 'other' metal detectorists to the point of closing down any possible dialogues or ways forward.

\section{References}

Bland, R., 2005. A pragmatic approach to the problem of portable antiquities: the experience of England and Wales. Antiquity, 79(304): 440-447. 
Deckers, P., Bleumers, L., Ruelens, S., Lemmens, B., Vanderperren, N., Marchal, C., Pierson, J., \& Tys, D. 2006. MEDEA: Crowd-Sourcing the Recording of Metal-Detected Artefacts in Flanders (Belgium). Open Archaeology, 2(1): 264-277.

Dobat, A., \& Jensen, A. T. 2016. "Professional Amateurs". Metal Detecting and Metal Detectorists in Denmark. Open Archaeology, 2(1): 70-84.

Fernández Cacho, S., \& García Sanjuán, L. 2000 Site looting and the illicit trade of archaeological objects in Andalusia, Spain. Culture without Context, 7: 17-24.

Hardy, S. 2017. Quantitative analysis of open-source data on metal detecting for cultural property: Estimation of the scale and intensity of metal detecting and the quantity of metal-detected cultural goods. Cogent Social Sciences, 3.

Immonen, V. \& Kinnunen, J. 2014. Metallinilmaisin, harrastajat ja kulttuuriperintö - kärjistyksistä yleiskuvaan. In: R. Vanhatalo, ed. Kotiseutu (101 vuosikerta). Helsinki: Suomen Kotiseutuliitto, pp. $107-113$.

Pitblado, B., \& Shott, M. eds. 2015. Special Section: Pros and Cons of Consulting Collectors. The SAA Archaeological Record, 15(5): 11-39.

Pyburn, K. A. 2011 Engaged Archaeology: Whose Community? Which Public? In; K. Okamura \& A Matsuda, eds. New Perspectives in Global Public Archaeology. New York: Springer, pp. 29-41.

Siltainsuu, J. \& Wessman, A. 2014. Yhteistapahtumia ja esineiden tunnistusta: Espoon kaupunginmuseon metallinilmaisinyhteistyö vuonna 2014. Muinaistutkija, 3: 34-40.

Suopajärvi, T. 2014. Lived, sensed and contested: Ageing in a smart city. In: Proceedings of the 6th Annual Architectural Research Symposium in Finland 2014. Oulu: University of Oulu, Department of Architecture, Publications A61, pp. 5-6. 
Thomas, S. 2013. Editorial: Portable Antiquities - Archaeology, Collecting, Metal Detecting. Internet Archaeology, 33.

Thomas, S., \& Campbell, S. eds. 2013. Portable Antiquities: Archaeology, Collecting, Metal Detecting. Internet Archaeology, 33.

Thomas, S., \& Stone, P.G. eds. 2009. Metal Detecting and Archaeology. Woodbridge: The Boydell Press.

Wade-Martins, P. forthcoming. An Archaeologist in an Arable Landscape. Oxford: Archaeopress.

Wessman, A., forthcoming. Searching for the past: Metal detecting and its impact on cultural heritage in Finland. In: M. Bintley, J. Hines, A. Richardson, A. Seaman \& E. Swift, eds, Neue Studien Zur Sachsenforschung. Stuttgart: Konrad Theiss Verlag. 